\title{
The seasonal cycle of the Atlantic Jet dynamics in the Alboran Sea: direct atmospheric forcing versus Mediterranean thermohaline circulation
}

\author{
Diego Macias $^{1} \cdot$ Elisa Garcia-Gorriz ${ }^{1} \cdot$ Adolf Stips $^{1}$
}

Received: 4 June 2015 / Accepted: 13 December 2015 /Published online: 4 January 2016

(C) The Author(s) 2015. This article is published with open access at Springerlink.com

\begin{abstract}
The Atlantic Jet (AJ) is the inflow of Atlantic surface waters into the Mediterranean Sea. This geostrophically adjusted jet fluctuates in a wide range of temporal scales from tidal to subinertial, seasonal, and interannual modifying its velocity and direction within the Alboran Sea. At seasonal scale, a clearly defined cycle has been previously described, with the jet being stronger and flowing towards the northeast during the first half of the year and weakening and flowing more southwardly towards the end of the year. Different hypothesis have been proposed to explain this fluctuation pattern but, up to now, no quantitative assessment of the importance of the different forcings for this seasonality has been provided. Here, we use a 3D hydrodynamic model of the entire Mediterranean Sea forced at the surface with realistic atmospheric conditions to study and quantify the importance of the different meteorological forcings on the velocity and direction of the $\mathrm{AJ}$ at seasonal time scale. We find that the direct effects of local zonal wind variations are much more important to explain extreme collapse events when the jet dramatically veers southward than to the seasonal cycle itself while sea level pressure variations over the Mediterranean seem to have very little direct effect on the AJ behavior at monthly and longer time scales. Further model results indicate that the annual cycle of the thermohaline circulation is the main driver of the seasonality of the AJ dynamics in the model simulations.
\end{abstract}

Responsible Editor: Aida Alvera-Azcárate

Diego Macias

diego.macias-moy@jrc.ec.europa.eu

1 European Commission, Joint Research Centre, Institute for Environment and Sustainability, Via E. Fermi, 2749, CP-21027 Ispra, Italy
The annual cycles in local wind forcing and SLP variations over the Mediterranean have no causal relationship with the $\mathrm{AJ}$ seasonality.

Keywords Numerical modeling · Atlantic Jet · Alboran Sea · Mediterranean Sea

\section{Introduction}

The Alboran Sea is the unique connection between the Mediterranean basin and the open Atlantic Ocean. Water and substance interchanges take place through the narrow Strait of Gibraltar where a typical anti-estuarine circulation is present; a surface inflow of relatively fresh and nutrient poor Atlantic waters and a deep outflow of salty and nutrient-rich Mediterranean waters (Armi and Farmer 1988). Such interchanges are fundamental for the matter budget of the semi-enclosed Mediterranean Sea (Macías et al. 2007a; Huertas et al. 2012) and also for the hydrodynamics (García-Lafuente et al. 2002) and biogeochemistry of the Alboran Sea itself (e.g., Ruiz et al. 2001; Sarhan et al. 2000; Macías et al. 2008).

The entrance of the Atlantic Jet (AJ) through the strait drives the main circulation of the Alboran Sea, with two anticyclonic gyres: the more permanent Western Anticyclonic Gyre (WAG) and the more elusive Eastern Anticyclonic Gyre (EAG) in the open-sea regions (e.g., Lacombe 1971; Lanoix 1974; Arnone et al. 1990; La Violette 1984) and smaller cyclones along the northern and southern shores (e.g., Peliz et al. 2013). The presence of the AJ close to the northern shore of the Alboran Sea favors the onset of upwelling conditions (Macías et al. 2008) that increase primary production in the region (García-Gorriz and Carr 1999; Macías et al. 2007b) and favors the spawning and recruitment of small pelagic fish (Catalán et al. 2013) that sustains an economically important 
fishing activity in the region (Macías et al. 2014a). The interannual variability of this fishery is also strongly linked to the circulation conditions created by the AJ dynamics, as recently described by Ruiz et al. (2013).

The scales of variability affecting the interchange at the Strait of Gibraltar (and, hence, the AJ dynamics) are wide and go from tidal (e.g., Bruno et al. 2002; García-Lafuente et al. 1998; Macías et al. 2006; Sánchez-Garrido et al. 2013; Sannino et al. 2002, 2004) to subinertial (Macías et al. 2007b; Vázquez et al. 2008; Ramírez-Romero et al. 2013), seasonal (Garret et al. 1990), and interannual (Peliz et al. 2013) time scales.

At seasonal scale, the AJ and associated circulation within the Alboran Sea has been described to oscillate between two main circulation modes (e.g., Vargas-Yáñez et al. 2002). During the end of fall beginning of winter, the AJ flows with lower speed (Viúdez et al. 1996, 1998) and with a more southerly direction (Macías et al. 2008) presenting the Alboran Sea a typical "one-gyre" configuration (Renault et al. 2012). In spring/summer period, on the other hand, the AJ typically increases its flowing speed (Vargas-Yáñez et al. 2002; Peliz et al. 2013) with a more northerly direction (e.g., Macías et al. 2008 ) and feeding the typical "two-gyres" circulation in the open Alboran Sea (Renault et al. 2012; Peliz et al. 2013).

Atmospheric conditions have been usually invoked as the main factors controlling the intensity and direction of the $\mathrm{AJ}$ at subinertial scale (Crepon 1965). Sea level pressure (SLP) variations over the western Mediterranean basin (Candela et al. 1989; García-Lafuente et al. 2002) and zonal wind in the Alboran Sea (Cheney and Doblar 1982; Sarhan et al. 2000; Macías et al. 2007a, b) are considered as the main forcings of the AJ. Both atmospheric conditions present a typical seasonal cycle (Candela et al. 1989; Dorman et al. 1995; Macías et al. 2007a, b), but it is yet to be determined if they are responsible and to what extent for the AJ seasonality described above.

Both wind and SLP are strongly correlated with each other (e.g., Crepon 1965); high SLP over the western Mediterranean basin typically corresponds with easterly winds over the Alboran Sea, while low SLP favors the presence of westerlies in Alboran. It is, thus, quite difficult to discriminate between these two forcing agents specially when using field data (e.g., Sarhan et al. 2000; Macías et al. 2008, 2009) as data collection is quite challenging in an environment such as the Strait of Gibraltar with intensive large-ships traffic and tidal currents with peaks over $4 \mathrm{~m} \mathrm{~s}^{-1}$. Remote sensing is not either particularly useful in this region due to the restricted extension of the strait itself and the coverage of actual satellite imagery records (such as those for sea level anomalies) that do not adequately cover this particular region (e.g., Navarro et al. 2011).

Numerical modeling could provide an adequate alternative to study this system and has been quite frequently used in recent years. Models have been used to study the hydrodynamic characteristics of the water interchange through the strait (e.g., Izquierdo et al. 2001; Sannino et al. $2002,2004,2007)$ and to assess the tidal influence on the biogeochemical conditions of the Atlantic inflow (Macías et al. 2007a) and on the position and behavior of the $\mathrm{AJ}$ in the NW Alboran Sea (Sánchez-Garrido et al. 2013). Interannual analysis of the baroclinic flows at the strait and of their relationship with observed atmospheric conditions have also been recently performed using numerical models by Peliz et al. (2013) and by Boutov et al. (2014).

However, a process-based study to clearly discriminate the effects of local (i.e., wind) versus remote (i.e., SLP) forcings over the seasonal AJ dynamics is still missing. In the present work, we use a 3D hydrodynamic model of the entire Mediterranean basin to analyze the reactions of the simulated $\mathrm{AJ}$ using real (from reanalysis data) atmospheric forcings and synthetic atmospheric conditions. We first compare the model results using realistic atmospheric forcings with satellitebased estimations of the AJ position and of the strength of the horizontal currents in the NW Alboran Sea to validate our modeling approach. Afterwards, we repeat the simulations (i) by removing the winds over the Alboran region, (ii) by imposing a constant (equal to its average value throughout the study period) SLP over the entire Mediterranean Sea, and (iii) by combining a constant SLP over the Mediterranean and no wind over the Alboran Sea. A final simulation was designed to largely increase vertical stratification (shutting down the thermohaline circulation) within the Mediterranean Sea by imposing zero wind velocity in the entire basin, no SLP variation, and no precipitation. AJ dynamics in each one of these five separated simulations are compared to quantify the importance of local and remote forcings on its seasonal cycle.

Model description, satellite-based altimetry measurements, and the different simulation set-ups are described in section 2 . Results are shown in section 3 and discussed in section 4 . Concluding remarks are presented in section 5 .

\section{Material and methods}

\subsection{Model description}

The 3D General Estuarine Transport Model (GETM) was used to simulate the hydrodynamics in the Mediterranean Sea. GETM solves the 3D hydrostatic equations of motion applying the Boussinesq approximation and the eddy viscosity assumption (Burchard and Bolding 2002). A detailed description of the GETM equations could be found in Stips et al. (2004) and at http://www.getm.eu.

The configuration of the Mediterranean Sea (Fig. 1) has a horizontal resolution of $5^{\prime} \times 5^{\prime}$ and includes 25 vertical layers. ETOPO1 (http://www.ngdc.noaa.gov/mgg/global/) was used 
Fig. 1 Mean climatologic simulated currents for the entire Mediterranean Sea (upper panel) and for the Alboran Sea (lower panel). Background color represents the velocity modulus $\left(\mathrm{m} \mathrm{s}^{-1}\right)$ and the arrows the current direction. The solid magenta arrows are a schematic representation of the mean currents redrawn from SiokouFrangou et al. (2010). Black box in the lower panel shows the exact region where the AJ angle and velocity are computed. Magenta box in the lower panel shows the region where the kinetic energy from altimetry data are computed

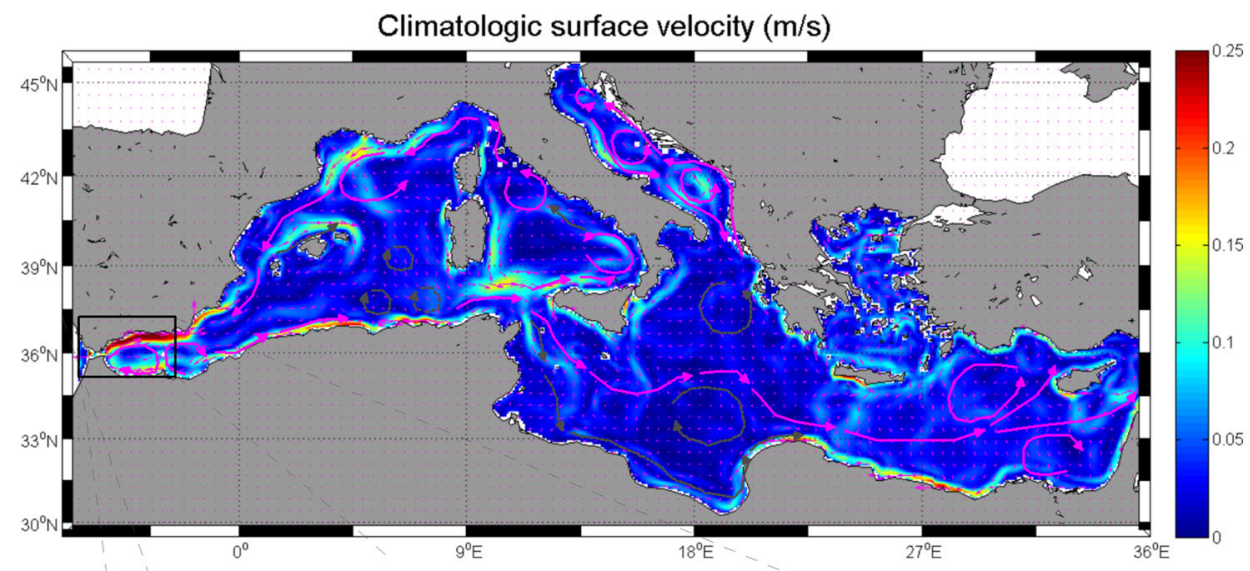

Climatologic surface velocity $(\mathrm{m} / \mathrm{s})$

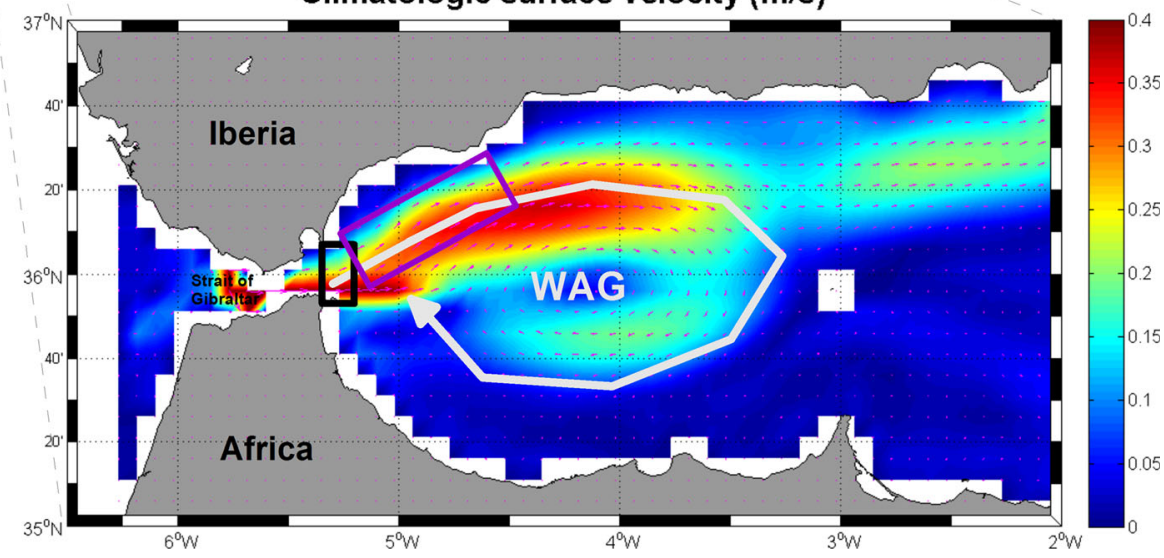

to build the bathymetric grid by averaging depth levels to the corresponding horizontal resolution of the model grid. The initial conditions are the salinity and temperature climatologies from the Mediterranean Data Archaeology and Rescue-MEDAR/MEDATLAS database (http://www.ifremer. $\mathrm{fr} /$ medar/).

Boundary conditions at the western edge of the domain were also computed from the MEDAR/MEDATLAS dataset imposing monthly climatological vertically explicit values of temperature and salinity. No horizontal currents were imposed at the open boundary. It has been demonstrated that for basinwide studies the location of this western boundary is not crucial (e.g., Macías et al. 2013, 2014c), but it does affects the performance of the model in the Alboran Sea in terms of absolute values of hydrological and biogeochemical properties (e.g., Macías et al. 2014b). In those previous works, the open boundary of the model was located right on the strait itself as their focus was on the basin-wide properties and not on regional scales. For the present work, being centered in the AJ dynamics, we decided to move this boundary towards the Gulf of Cadiz, at some $95 \mathrm{~km}$ westward of the strait (Fig. 1b) to try minimizing any interference with the internal dynamics of the model.

The present configuration of the model includes 37 rivers discharging along the Mediterranean coast. The corresponding river discharges were derived from the Global River Data Center (GRDC, Germany) database. Data gaps in fluxes from rivers where filled with climatological values.

The GETM configuration for the Mediterranean Sea is forced at surface every $6 \mathrm{~h}$ using European Center for Medium Range Weather Forecast (ECMWF) datasets available from http://www.ecmwf.int. ERAin data (Dee et al. 2011) is used to force the model for the period 1989 to 2012. From ERAin dataset, wind velocity at $10 \mathrm{~m}$ (u10 and v10), air temperature at $2 \mathrm{~m}$ ( $\mathrm{t} 2$ ), dew point temperature (d2), cloud cover (tcc), and sea level pressure (SLP) are used to force the ocean model. For the simulations described below using synthetic atmospheric conditions, the two most important variables are wind velocities and SLP. Wind velocities are used to compute the winddrag induced at the surface layer of the ocean while the gradient of SLP is added to the sea surface slope to calculate the total barotropic pressure gradient (Kantha and Clayson 2000). 
Model internal (barotropic) integration time step was $27 \mathrm{~s}$ while external (baroclinic) time step was $540 \mathrm{~s}$. Monthly mean values of all hydrodynamics variables were stored throughout the entire simulation time span.

This same model configuration has been used to successfully represent the sea surface temperature patterns in the Mediterranean Sea during the last 50 years (Macías et al. 2013) and also the present day conditions of the pelagic ecosystem when coupled to a biogeochemical model (Macías et al. 2014b). To avoid the effects of initial conditions, only the final 16 years (1996-2012) of the simulation period are used to compare with satellite data (see below).

$\mathrm{AJ}$ angle and velocity were computed by averaging the " $\mathrm{u}$ " and " $v$ " velocities in the upper $10 \mathrm{~m}$ of the water column at the eastern sector of the Strait of Gibraltar (black box in lower panel of Fig. 1). This area was selected to include the entire region where the $\mathrm{AJ}$ could be located at the eastern side of the strait. Six nodes of the model grid are included within the analyzed region. The $\mathrm{AJ}$ mean velocity vector was computed as the average value within the box and the standard deviations of the mean " $u$ " and " $v$ " value where considered as computational errors and used to construct the error bars in Fig. 2.

\subsection{Satellite data}

In the present work, we have used the 4-km monthly sea surface temperature satellite images (SST) from the Advanced Very High-Resolution Radiometer (AVHRR) Pathfinder Version 5 (available until 2009) and from the MODIS Aqua Level 3 (from 2009 onward). Both satellite SST datasets were obtained from the Physical Oceanography Distributed Active Archive Center (PO.DAAC) at the NASA Jet Propulsion Laboratory, Pasadena, CA (http://podaac.jpl.nasa.gov). Those datasets represent a reanalysis of historical SST data that have been improved through extensive calibration and validation and using any other available information to yield a consistent research-quality time series for global climate studies.

To calculate the AJ angles from satellite SST distributions, we benefit from the distinctive thermal signature of the Atlantic water entering the Alboran Sea. In general, the SSTs of the AJ are in contrast with the local Alboran Sea SSTs and in most monthly SST images the AJ progression in the basin can be detected throughout the year. Specifically, we use the gradient function in Matlab ${ }^{\circledR}$ to obtain the gradient field of SST in the region defined by the black box in the lower panel of Fig. 1 . Secondly, we calculate the direction which is perpendicular to the main SSTs gradient which would correspond to an estimation of the angle of entrance of the AJ into the Alboran Sea. Though useful, these satellite-derived angles should not be considered as an absolute quantification of the AJ angle but as an illustrative approximation of the AJ progression when entering the Alboran Sea.

Additionally, altimetry data (absolute dynamic topography, ADT) from AVISO (http://www.aviso.oceanobs.com) at 1/8 spatial resolution were used to compute the kinetic energy (KE) of the NW region of the Alboran Sea (magenta box in Fig. 1, lower panel). KE from calculated geostrophic velocities in the region from 1990 to 2012 have been analyzed by Ruiz et al. (2013) extracting the main temporal variance modes of the circulation in the area by a singular value decomposition technique (Bretherton et al. 1992). We have used the same KE data shown in Fig. $2 c$ of their paper to create a climatologic cycle to compare with the seasonal cycle of the AJ direction simulated by our model (see black line in Fig. 2b).

\subsection{Simulations with modified atmospheric conditions}

Four simulations with synthetic atmospheric forcings were designed to discriminate between the local effects of wind forcing at the Alboran Sea and the remote forcing by SLP variations over the western Mediterranean Sea. In the first experiment (R1, Table 1), wind velocity was set to zero in a $5^{\circ} \times 5^{\circ}$ box centered at $36^{\circ} \mathrm{N}, 5^{\circ} \mathrm{W}$ (the eastern end of the Strait of Gibraltar) while the other atmospheric variables and model set-up remained untouched. In the second experience (R2, Table 1), the SLP over the entire model domain was set constant to its average value throughout the study period $(\sim 1016 \mathrm{hPa})$. As in the previous experiment, the rest of atmospheric conditions and model set-up were not changed. The third experiment (R3, Table 1) was done combining the two above, i.e., without winds over the Alboran Sea-Gulf of Cadiz region and no SLP variations in the entire model domain. In the last simulation (R4, Table 1), winds were set to zero throughout the entire model domain, SLP was kept constant and precipitation was eliminated. The main objective of this last simulation was to increase vertical stratification in the basin and stop the deep-water formation during winter time.

\section{Results}

Climatologic mean surface currents during the simulation period for the reference run (RR, Table 1) are show in Fig. 1 for the entire model domain (upper panel) and for the Alboran Sea (lower panel). The main currents of the basin are reproduced by the model such as the Algerian current flowing eastward along the African coast in the western basin, the northern current moving westward along the coasts of southern France, the general anticyclonic circulation of the eastern basin, and the quasi-permanent anticyclonic gyre at the southern Adriatic Sea (see the schematic mean circulation shown in Fig. 1 redrawn from Siokou-Frangou et al. 2010). 
a

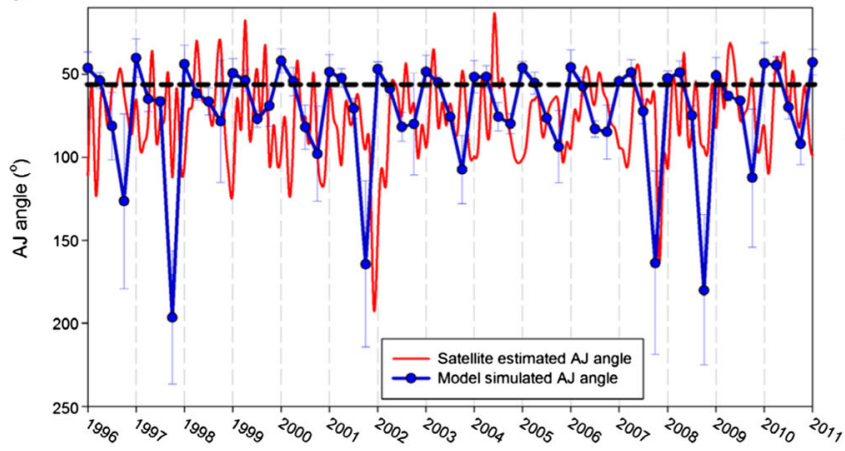

b

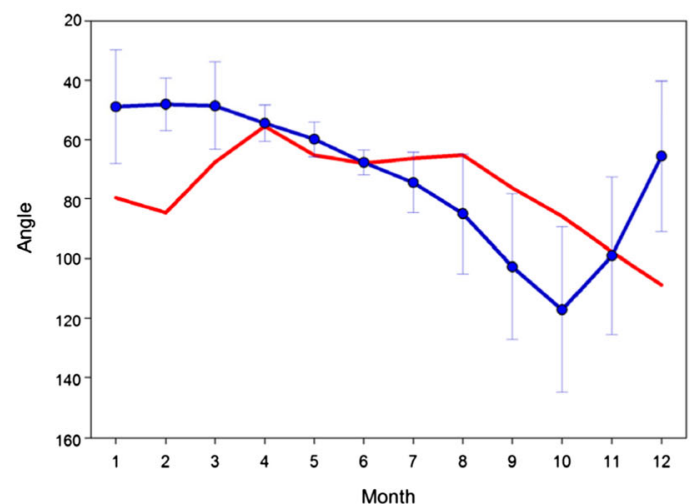

Fig. 2 a Time evolutions of satellite-estimated angles of the AJ (red line) and of simulated angles (blue line) from the model simulation. Angles are defined with respect to the north (considered as $0^{\circ}$ ). The horizontal discontinuous black line indicates the position of the main axis of the strait as defined by the bathymetry. b Climatologic seasonal cycle of observed (red line) and simulated (blue line) AJ angles. c. Time series

Within the Alboran Sea, the WAG could be easily seen (white arrow in Fig. 1, lower panel) with a center at around $35.9^{\circ} \mathrm{N}, 4.2^{\circ} \mathrm{W}$. The climatologic currents do not show the more elusive EAG as the AJ did not totally detach from the Spanish shore but continues to flow along the coast.

The time evolutions of satellite-derived and modelsimulated angles of the AJ are shown in Fig. 2a. Satellite estimations present higher variability than model simulations but the mean values of the angles are quite similar in the satellites $\left(75.2^{\circ} \pm 11.3^{\circ}\right)$ and in the model $\left(84.48^{\circ} \pm 8.1^{\circ}\right)$. There is also a clear seasonal cycle in both time series, with smaller angles (more northerly direction) during the springsummer and larger angles (more southerly) during fall-winter as clearly seen in Fig. 2b. In spite of the general good

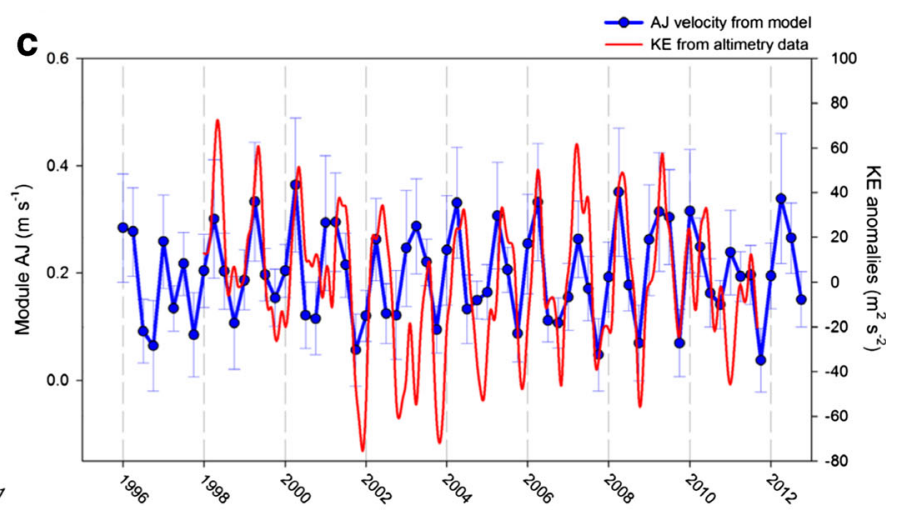

d

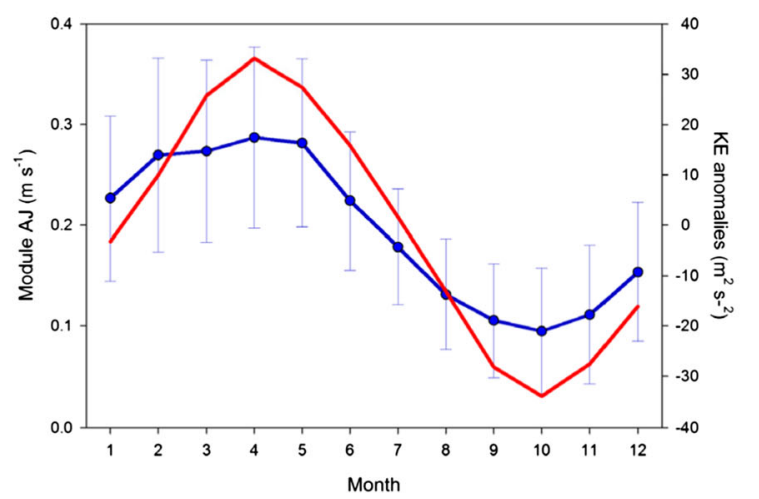

of monthly KE anomalies in the NW Alboran Sea from altimetry data (red line) and of simulated AJ velocities (blue line) from the model simulations. d Climatologic seasonal cycle of $\mathrm{KE}$ anomaly (red line) and model-derived AJ velocity (blue line). Error bars in the different panels are based on the standard deviations of the mean " $u$ " and "v" values computed within the black box in Fig. 1 as indicated in the text

agreement between satellite-estimated angles and model simulations, there are some clear mismatches between the two series. For example, there are two southward migrations of the AJ simulated in the model in fall of years 1997 and 2008 that are not apparent in the satellite estimates (Fig. 2a), and also it seems that the seasonal cycles are shifted by approximately 1 month (Fig. 2b).

A singular spectrum analysis (Fig. 3a) of the two angle time series in Fig. 2a indeed reveals the presence of predominant annual cycles representing $\sim 27$ and $\sim 36 \%$ of the total variability in the satellite and model estimation, respectively. These annual signals are determined in both cases by eigenvectors $\# 1$ and $\# 2$ being also significantly correlated $(R=0.45$, $p<0.01$ ), although (as indicated above) there is slight shift

Table 1 Main characteristics

\begin{tabular}{ll}
\hline Simulation & Atmospheric conditions \\
\hline RR & ERAin unaltered forcing \\
R1 & No wind (u10 $=$ v10 $=0$ ) over the Alboran Sea \\
R2 & No SLP variations over the Mediterranean Sea \\
R3 & No wind over the Alboran Sea and no SLP variations over the Mediterranean Sea \\
R4 & No wind, no SLP variations, and no precipitation over the Mediterranean Sea \\
\hline
\end{tabular}


with the modeled angle leading the satellite estimates by 1 month (Fig. 3b). The spectral decomposition of both angles' time series shown in Fig. 3a also indicates that there is a considerable fraction of the energy associated to eigenvectors $\# 3$ to \#20 as all of them represent variability levels above $1 \%$. If the signal associated to these 18 eigenvectors is computed, very irregular time series are obtained (Fig. 3c) for both satellite and model estimations. In both cases, however, the mean value of this residual signal is practically identical $\left(\sim 75^{\circ}\right.$ for satellite data and $\sim 72^{\circ}$ for model) containing, also, some of the most prominent southward excursion of the jet as at the end of 2001 and 2007.

On the other hand, also the time series of KE anomalies in the NW Alboran Sea (red line in Fig. 2c) shows a similar pattern to the simulated AJ velocities (blue lines in Fig. $2 \mathrm{~b}$ ) with a statistically significant correlation $(R=0.6, p<0.01)$. Climatologic cycles of KE in the NW Alboran Sea and simulated AJ velocity (Fig. 2d) show a similar seasonality with larger values during winter/spring and a marked minimum at the end of autumn. Clearly, when the AJ is directed southward (large angle values), the water movement and associated KE in the NW Alboran Sea reduce.

There is, thus, a characteristic relationship between simulated angles and modules of the AJ (Fig. 4). With high velocity (above $\sim 0.3 \mathrm{~m} \mathrm{~s}^{-1}$ ), the AJ seems to be locked at an angle $\sim 60^{\circ}$. This situation of the AJ is associated with westerly winds (positive value of the zonal component, Fig. 4) and with low SLP anomalies (computed with respect to the temporal mean SLP value during the simulation period) over the western Mediterranean basin. With relatively lower AJ module $\left(0.2-0.3 \mathrm{~m} \mathrm{~s}^{-1}\right.$ ), the angle increases to $\sim 67^{\circ}$ (Fig. 4) while the zonal wind in the Alboran Sea are still from the west by of lower intensity and the SLP anomaly over the western Mediterranean is positive. Finally, when the module of the $\mathrm{AJ}$ is below $0.1 \mathrm{~m} \mathrm{~s}^{-1}$, its mean angle increases up to $118^{\circ}$ but presenting a much higher dispersion than with higher velocities (Fig. 4). The winds over the Alboran Sea are clearly directed eastwards (negative zonal value) and the SLP anomaly over the western Mediterranean is markedly positive (Fig. 4).

From the analysis in Fig. 4, it is not straightforward to infer which meteorological variable (local zonal wind or SLP anomalies over the western Mediterranean) is controlling the dynamics of the AJ at monthly time scale. Both are, indeed, clearly linked, with negative SLP monthly anomaly corresponding with westerly winds and positive SLP monthly anomaly with easterlies (Fig. 5a). Henceforth, there is a positive correlation between the mean monthly AJ velocity and the monthly mean zonal wind (Fig. 5b) and a negative correlation between AJ monthly velocity and mean monthly SLP anomaly (Fig. 5). The scatter plots of the monthly mean angle of AJ versus the different meteorological variables (Fig. $5 \mathrm{~d}$, e) did not show such clear relationships. It seems, however, that significant southward migration of the AJ only happen with easterlies winds while no clear correlation is found with monthly SLP anomalies.

Results from the three first simulations with modified atmospheric forcings (Table 1) are shown in Fig. 6 along with the results of the RR simulation (gray symbols and lines in Fig. 6). In the left column, results from the R1 experiment (no surface wind from the Alboran Sea region) are shown. The time evolution of the AJ angle (black line in Fig. 6a) is quite similar to the RR (gray line in same figure). The most important differences could be found in the two extreme collapse events simulated at the end of 2001 and 2007 in RR. When wind over Alboran Sea is set to zero, the AJ did not suffer such strong southward migrations, especially for year 2001. Regarding seasonality, the cycles are almost identical in RR and R1. The characteristic relationship between module and angle of the $\mathrm{AJ}$ (see Fig. 4) is maintained when no wind on Alboran Sea is considered (Fig. 6b), and now the larger jet velocities are associated with negative SLP anomalies over the western Mediterranean while a weaker AJ typically happens when SLP anomaly is positive.

The results from the simulation with a constant SLP over the entire model domain (Fig. 6, central column) are quite similar to those of the complete run. In the time evolution of the AJ angle (Fig. 6c), both time series are almost identical, with the same seasonal oscillations and the same "collapse" events in 2001 and 2007. Also, the relationship between AJ module and angle is similar to the one observed in the complete simulation (Fig. 6d) and a clear separation between westerly and easterly conditions is found (blue and red symbols, respectively, in Fig. 6d); a strong AJ is usually associated with westerlies while a weaker AJ is typically associated with more easterly winds.

Finally, when both atmospheric modifications are combined (no winds on Alboran Sea and no SLP variations) the temporal evolution of the simulated $\mathrm{AJ}$ angle (black line in Fig. 6e) is very similar to the results obtained only removing local wind forcing (Fig. 6a). The seasonal cycle is still present but the collapse events are largely reduced. The module-angle relationship for this simulation (Fig. 6f) shows the wellknown pattern explained before, but in this case, the dispersion of the scatter cloud is reduced indicating a much smoother behavior of the AJ.

In none of the experiments above, the seasonal cycle of the AJ has been dramatically altered so a final simulation (R4) was performed increasing the vertical stratification of the Mediterranean basin and, hence, reducing the thermohaline circulation (MTHC). The objective of this experiment was to test if the AJ dynamics was substantially altered by changes in the MTHC strength. The mean climatologic mixed layer depth (MLD) during the winter (January, February, and March months (JFM)) is shown for the simulation using the complete atmospheric forcing in Fig. 7a and for the simulation with no 
Fig. 3 Spectral analysis of satellite-derived and modelsimulated AJ angles time series. a Spectral energy distribution in the first 40 eigenvectors obtained from the SSA decomposition. $\mathbf{b}$ Annual signals defined by the first two (more energetic

eigenvectors). c Residual signals defined by eigenvectors 3 to 20 (those with energy levels $>1 \%$ in (a)
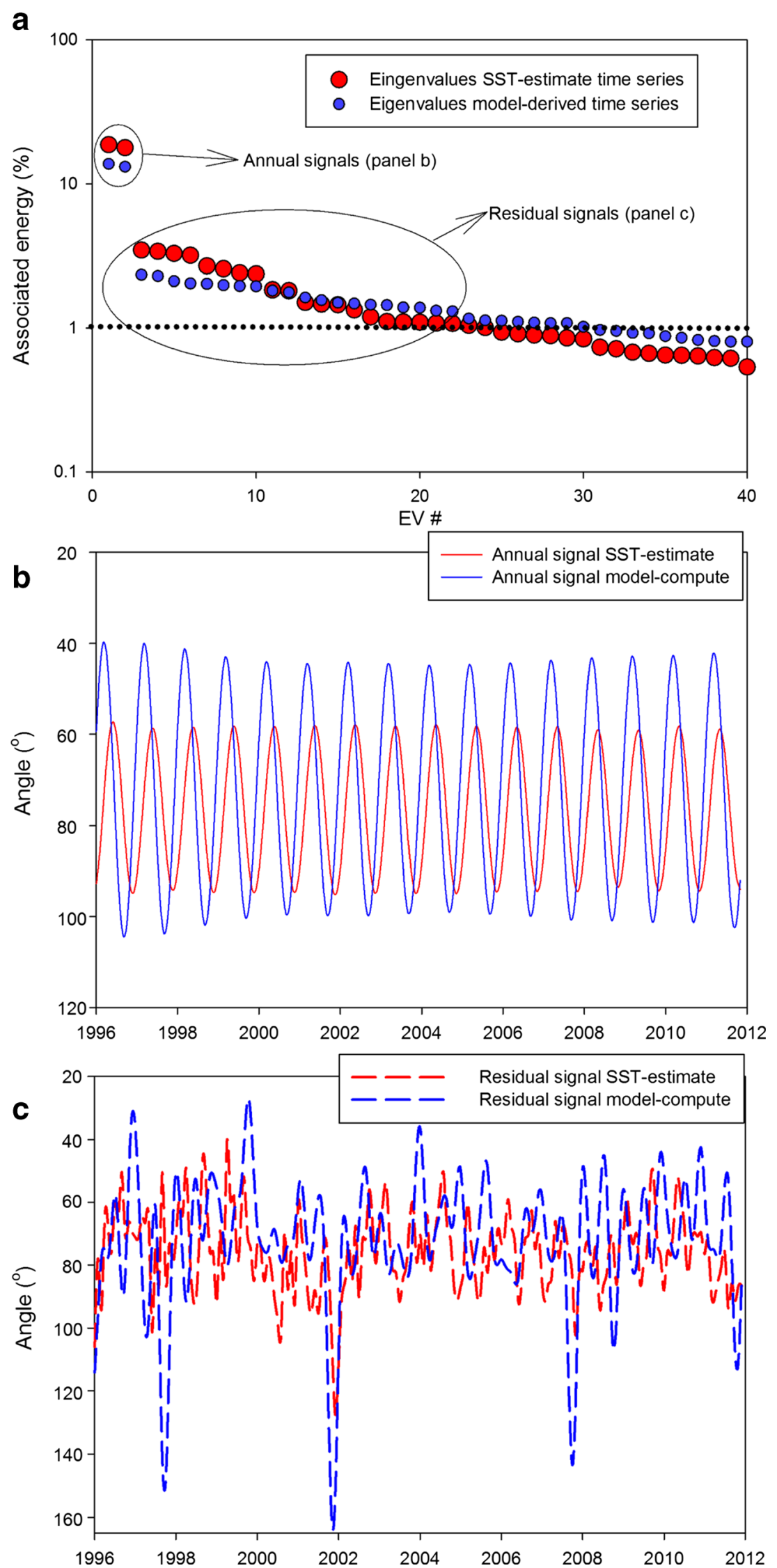


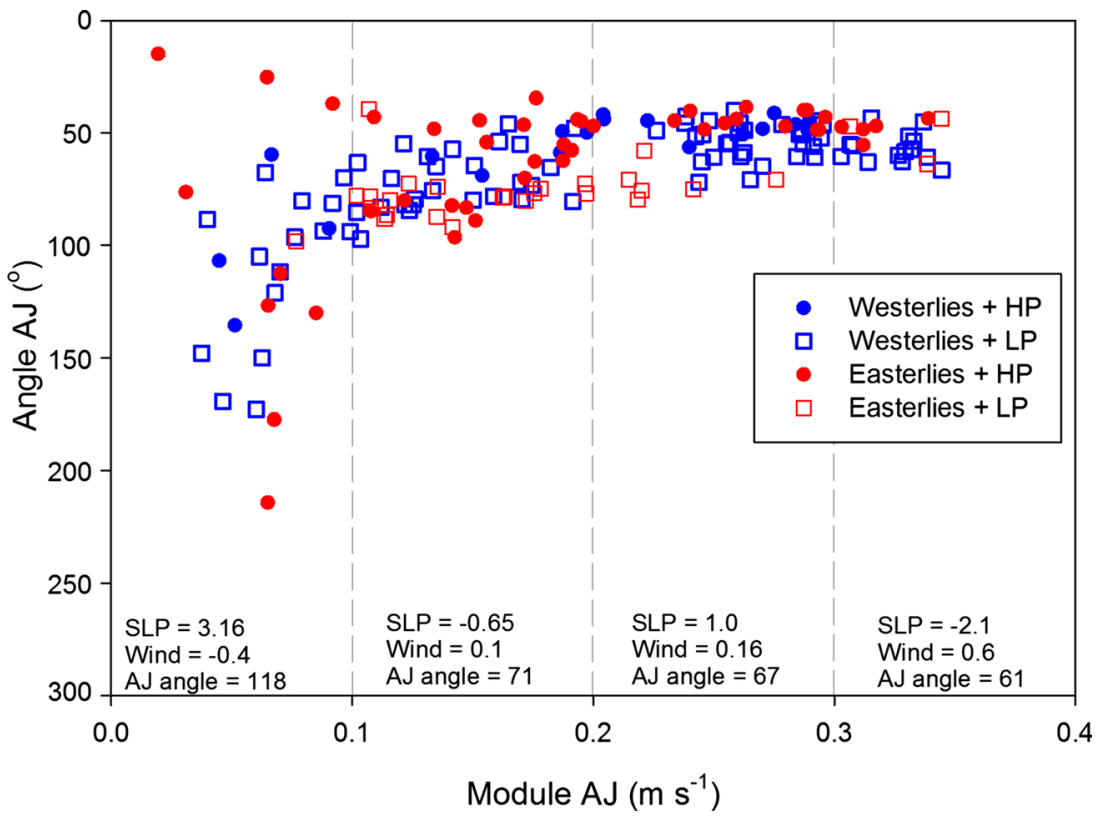

Fig. 4 Scatter plot of simulated AJ velocity $\left(\mathrm{m} \mathrm{s}^{-1}\right)$ and angle $\left(^{\circ}\right)$. Blue dots correspond to a situation of westerlies (positive zonal wind) and negative SLP anomalies over western Mediterranean. Blue squares to a situation of westerlies but with positive SLP. Red dots correspond to easterlies (negative zonal wind) and positive SLP anomaly. Red squares

wind, no SLP variations and no precipitation in the entire model domain in Fig. 7b. For the run using the complete atmospheric forcing, it is easy to identify the typical zones for deep water formation in the Gulf of Lion (GoL), in the southern Adriatic Sea and around the Crete island (magenta stars in Fig. 7a). On the contrary, with the manipulated atmospheric conditions, the winter MLD is severely reduced in the entire basin with absolute maximum climatologic values of $87 \mathrm{~m}$. This is also clear examining the annual time series of winter MLD extracted for the three locations marked in Fig. 6a, b (Fig. 7c). In the case of the full atmospheric forcing, the winter MLD in the GoL could reach values close to $1600 \mathrm{~m}$ with a mean value of $797 \mathrm{~m}$. Also, in the Adriatic and Crete sites, the winter MLD could reach values over $500 \mathrm{~m}$ with mean values of 412 and $392 \mathrm{~m}$, respectively. For the modified atmospheric forcing, the maximum winter MLD is not larger than $82 \mathrm{~m}$ in any of the three sites with mean values of 66, 74, and $44 \mathrm{~m}$ for the GoL, Adriatic, and Crete, respectively. It can, thus, be reasonably assumed that deep water formation has been effectively stopped with the modified atmospheric forcings in this last experiment.

The AJ dynamics for this latter simulation (Fig. 8) is clearly different to what has been observed so far. The time series of the AJ angle (black line in Fig. 8a) shows a quasi-constant flow in the direction of $270^{\circ}$, i.e., the surface water is flowing westward (outflow) through the Strait of Gibraltar. Indeed, for this simulation a complete reversion of the circulation in the strait is simulated with a water inflow occurring at depth (not correspond to easterlies and negative SLP anomalies. Inserted in the figure are the values of the mean SLP anomaly, mean zonal wind, and mean AJ angle for different ranges of AJ velocities. SLP anomalies are computed with respect to its mean value throughout the entire simulation period

shown). A spectral analysis of the R4 simulated AJ angle (not shown) reveals that still an annual signal is the main contributor to the variability of the series $(\sim 25 \%)$ but with a much smaller oscillation range $\left(\sim 10^{\circ}\right)$ than in the RR (see for example Fig. 2b). Logically, the normal module-angle relationship for this simulation is not present anymore (Fig. 8b) with the entire scatter concentrated around $270^{\circ}$ direction and $0.219 \mathrm{~m} \mathrm{~s}^{-1}$ velocity.

\section{Discussion}

On a regional scale, within the Alboran Sea, the model is able to simulate the main feature, the WAG, but not the more elusive EAG (e.g., Lacombe 1971; Lanoix 1974; La Violette 1984). In our model, the AJ did not detach from the Spanish coast westward of Malaga bay as usually described (e.g., Arnone et al. 1990) but continues alongshore without forming the EAG. The relative coarse horizontal resolution of the model or the smoothed topography used could be partially responsible for this misbehavior of the simulated currents in that region. The geometry and topography of the Alboran basin have been reported as crucial for determining the formation, size, and location of the gyres (e.g., Preller 1986; Werner et al. 1988; Herburn and La Violette 1990); however, for practical reasons (computational time and storage capacity), it is not possible for us to run the model with a finer resolution at least for long-term simulations. Nevertheless, future model 
Fig. 5 a Scatter plot of zonal wind $\left(\mathrm{m} \mathrm{s}^{-1}\right)$ in Alboran and SLP anomalies (hPa) over the western Mediterranean from the ERAin database. b Scatter plot of simulated AJ velocity $\left(\mathrm{m} \mathrm{s}^{-1}\right)$ and zonal wind in Alboran $\left(\mathrm{m} \mathrm{s}^{-1}\right)$. c Scatter plot of simulated AJ velocity $\left(\mathrm{m} \mathrm{s}^{-1}\right)$ and SLP anomalies (hPa) over the western Mediterranean. d Scatter plot of simulated $\mathrm{AJ}$ direction $\left(^{\circ}\right)$ and zonal wind in Alboran $\left(\mathrm{m} \mathrm{s}^{-1}\right)$. $\mathbf{e}$ Scatter plot of simulated AJ direction $\left(^{\circ}\right)$ and SLP anomalies $(\mathrm{hPa})$ over the western Mediterranean
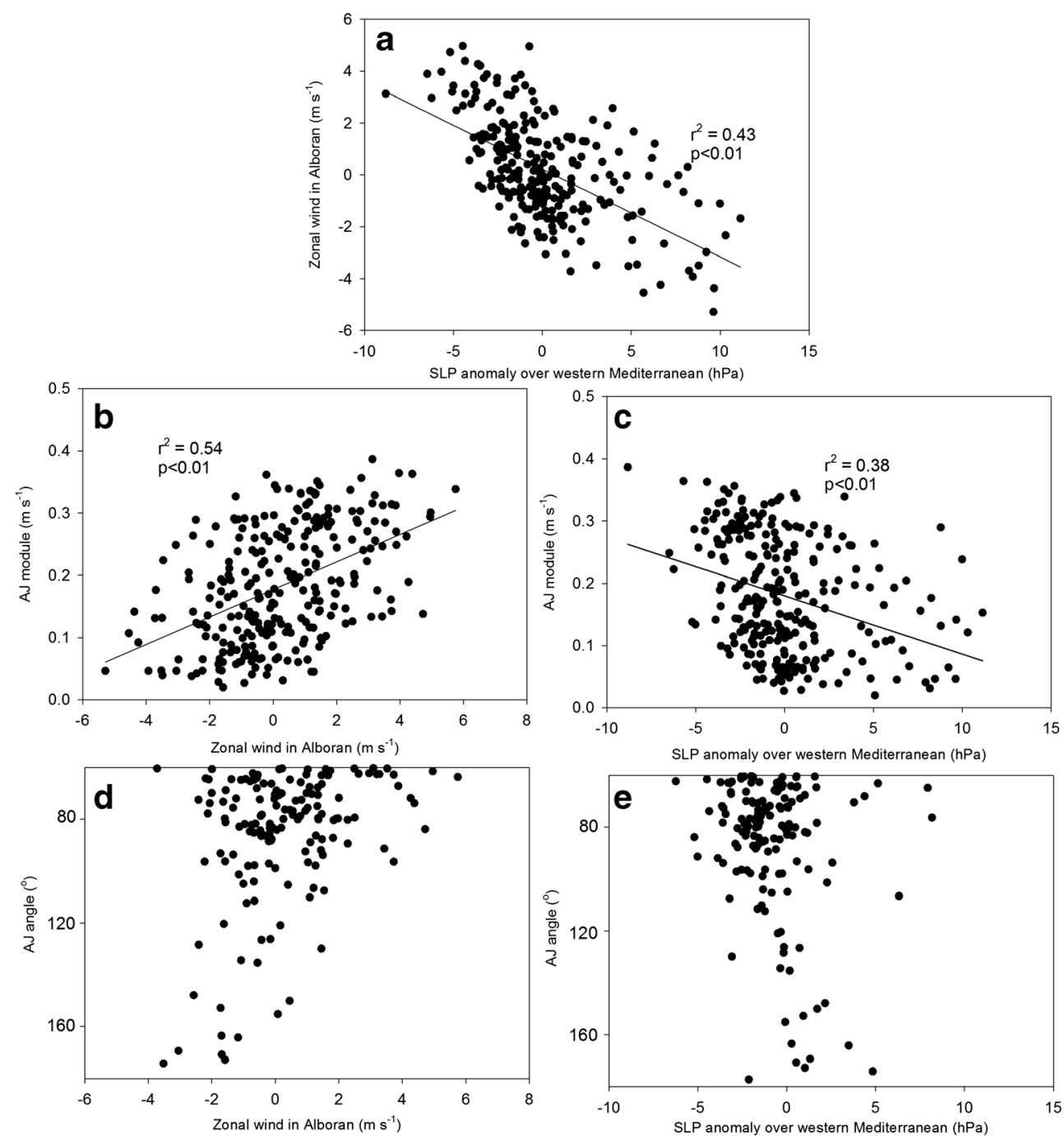

development should include some "nesting" to increase horizontal details in some specific areas of the basin and the Alboran Sea and, specially, the Strait of Gibraltar are suitable candidates.

The presence of the western boundary of the model domain in relative vicinity to the strait could also represent a source of problems from the model simulations even if it was located $\sim 90 \mathrm{~km}$ into the Gulf of Cadiz (see section 2.1). In order to test the importance of the location of the boundary, results from another simulation with the western boundary at the very west entrance of the strait (as described for example in Macías et al. 2013) were analyzed. The AJ angle-velocity relationship in this additional simulation was very similar to the one shown here in Fig. 4, although the absolute values (of both angle and velocity) were slightly different. This experience indicates that the vicinity of the boundary to the analyzed area does not introduce critical interferences on the AJ dynamics; however, locating it further away from the Strait (as done in all the simulations analyzed here) provides more confidence in the simulations results.
Independent of the above-mentioned problems, the AJ temporal dynamics seems to be fairly simulated by the model in the RR (Fig. 2). Both the seasonality and the interannual variability are quite similar in model results and in satellite estimations, although total variability is higher in the latter. Here, we must consider that the estimations of the AJ direction based on SST images are just an approximation, because the temperature front is only a crude proxy for indicating the AJ. In order to double check the validity of this method to infer the AJ direction, we applied the same protocol to the model simulated SST fields. This analysis (not shown) revealed that the angles computed from the velocity fields (i.e., the real angle of the simulated $\mathrm{AJ}$ ) and those estimated by the gradient method were very similar throughout the simulation period, with a mean difference of just $6.9^{\circ}$, representing an average error of $3 \%$ (if $180^{\circ}$ difference is considered as $100 \%$ error). This secondary analysis indicates that the SST gradient method is a good approximation to estimate the $\mathrm{AJ}$ angle in the studied region. 

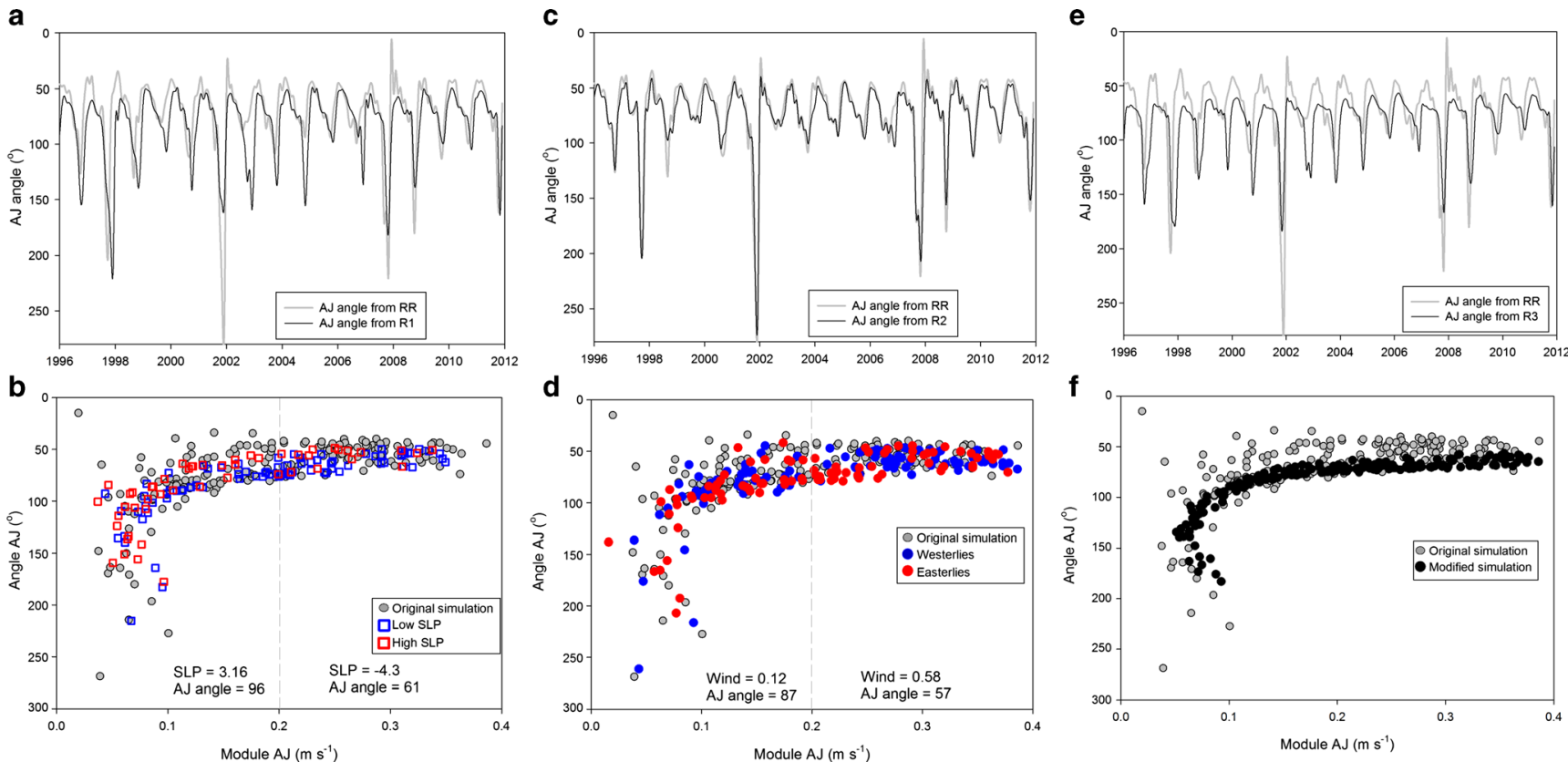

Fig. 6 a AJ angle time series from the original simulation (gray line) and from the no-wind over Alboran simulation (black line). b Module-angle relationship in the original simulation (gray symbols) and in the no-wind over Alboran simulation (color symbols). c AJ angle time series from the original simulation (gray line) and from the no-SLP variations over the Mediterranean Sea simulation (black line). d Module-angle relationship

in the original simulation (gray symbols) and in the no-SLP variations over the Mediterranean Sea simulation (color symbols). e AJ angle time series from the original simulation (gray line) and from the no-wind, noSLP variations simulation (black line). $\mathbf{f}$ Module-angle relationship in the original simulation (gray symbols) and in the no-wind, no-SLP variations simulation (color symbols)

a

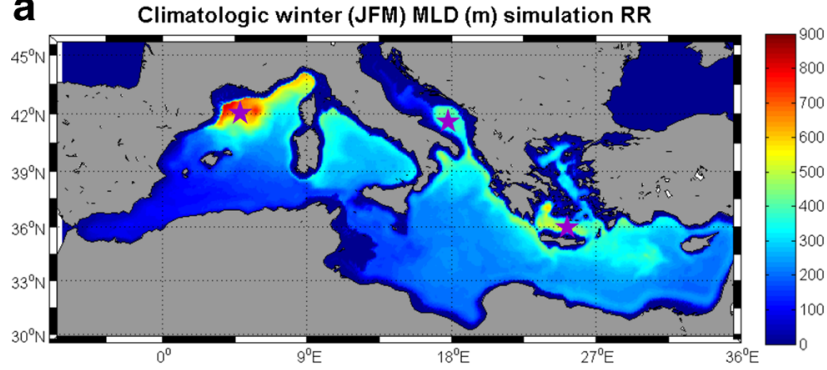

b

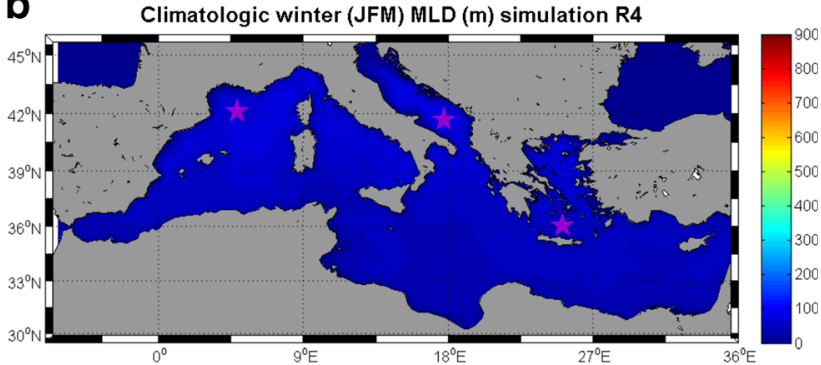

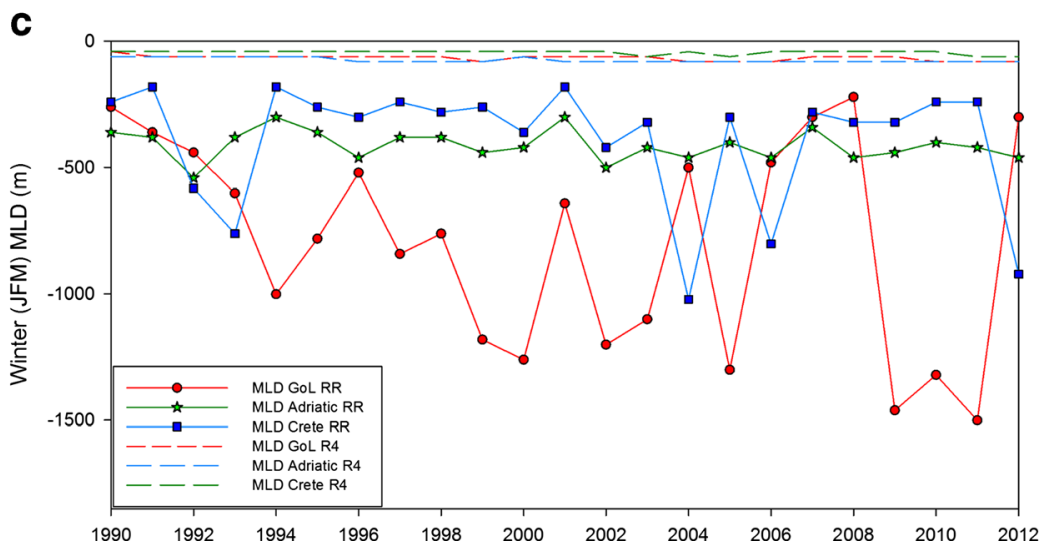

Fig. 7 a Climatologic winter (January, February, March) mixed water depth for the complete atmospheric forcing simulation. b Climatologic winter (January, February, March) mixed water depth for the simulation without wind, SLP variations, and precipitations over the whole model domain. c Winter mixed layer depth from the locations marked in (a) and (b). Solid lines indicate results from the complete atmospheric forcing simulation. Broken line indicates results from the modified atmospheric forcing simulation 


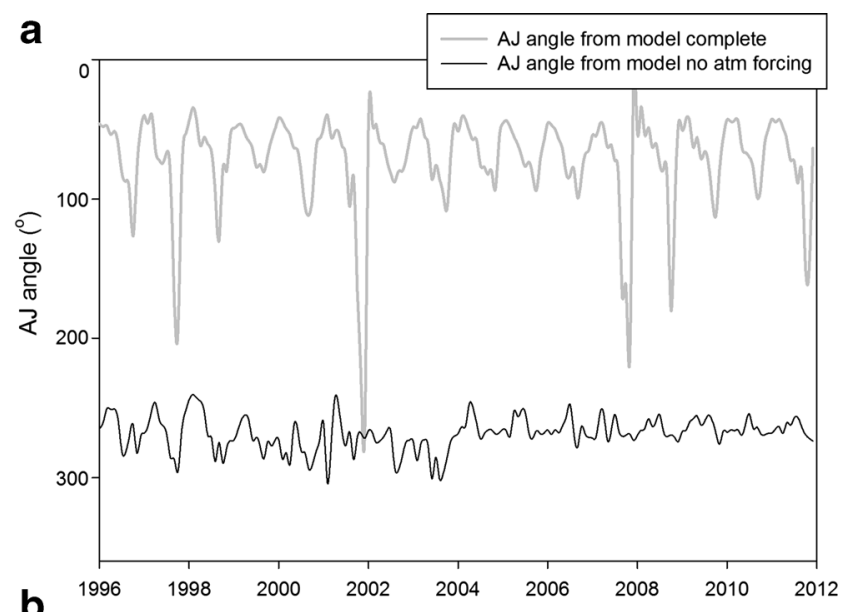

b

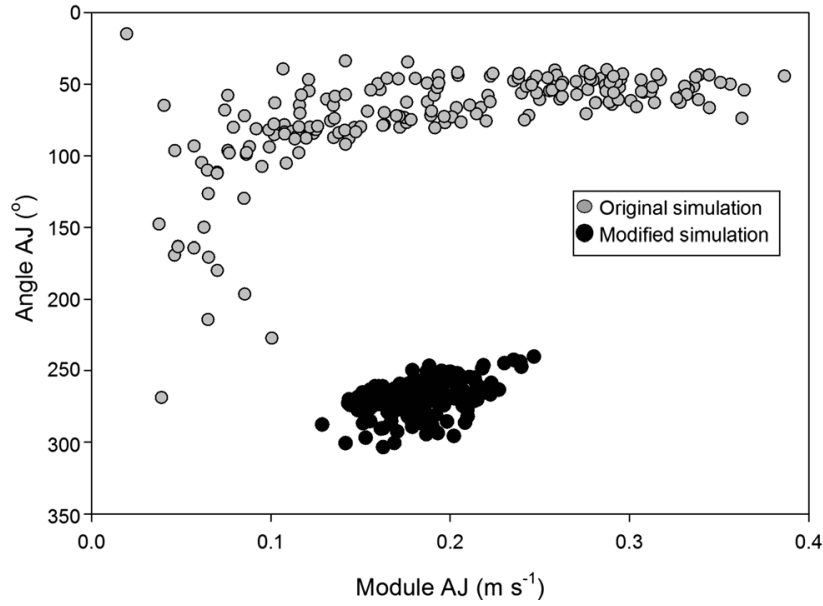

Fig. 8 a AJ angle time series from the original simulation (gray line) and from the no-wind, no-SLP variations, and no precipitation over the whole domain simulation (black line). b Module-angle relationship in the original simulation (gray symbols) and in the no-wind, no-SLP variations, and no precipitation over the whole domain simulation (black symbols)

Both time series of AJ angle (from model and satellite) present the typical seasonality previously described for the system, with the AJ moving northward during the late winter/spring months and southward during late fall (Viúdez et al. 1996; Vargas-Yáñez et al. 2002; Macías et al. 2008). The seasonal change in the direction of the AJ modifies the circulation pattern of the basin (Renault et al. 2012; Peliz et al. 2013) and the primary production rates induced at the coastal upwelling systems (e.g., Sarhan et al. 2000; Macías et al. $2007 \mathrm{a}, \mathrm{b})$. This seasonal pattern of the AJ angle is further confirmed by the altimetry data from the NW Alboran Sea. As discussed in Ruiz et al. (2013), the KE in this region is high (positive $\mathrm{KE}$ anomaly) when the $\mathrm{AJ}$ is flowing along the Spanish coast (low entrance angle), and correspondingly the energy is low (negative $\mathrm{KE}$ anomaly) when the AJ is diverted southward (larger entrance angle) away from the NW Alboran Sea. The good correlation between KE anomalies and simulated AJ velocity (Fig. 2c and d) further supports the validity of used modeling approach.
As the model seems to correctly reproduce the observed and reported seasonal pattern of the AJ, we can reasonably use it to try to elucidate the relative importance of local and remote atmospheric forcings on this dynamics. In Fig. 4, a distinct relationship between AJ velocity and angle could be easily seen. With high flow velocities, the angle seems to be "locked" at around $60^{\circ}$ with relative little variations. When the jet weakens, the direction is more variable from $40^{\circ}$ to $200^{\circ}$, although the mean angle increases up to $118^{\circ}$. This plot is indicating that with a strong enough jet, its angle is not very dependent of other variables. It continuously sticks to a certain position regardless of the zonal wind conditions and of the SLP over the western Mediterranean (as exemplified by the various symbols in Fig. 4). In this situation, the WAG is usually well developed being, thereby, a typical condition of the spring/summer months (Renault et al. 2012; Peliz et al. 2013).

When the AJ weakens, its angle starts to vary and moves northwards (less frequently) or southward (more frequently) as shown by the large dispersion of symbols in the left part of the graph at Fig. 4. The southward migration of the jet associated with small flow speeds has been previously reported from synoptic sampling combined with remote sensing images (Macías et al. 2008). Northward migrations during periods of low flow and predominant easterlies have also been documented (Perkins et al. 1990; García-Lafuente et al. 1998). Very likely, the variation of the AJ direction with low flowing velocity at synoptic scales is dependent on the general hydrological pattern of the western part of the Alboran basin as, for example, the extension and position of the WAG.

Also, from Fig. 4, a clear association between atmospheric conditions and $\mathrm{AJ}$ velocity could be observed. With westerly winds and low SLP anomaly over the western Mediterranean, the AJ velocity is usually high while with easterly winds and high SLP anomalies, the jet slows down. This is a known pattern already described from field data (García-Lafuente et al. 2002; Macías et al. 2008) and from modeling simulations (Candela 1991; Peliz et al. 2013) that is created by the strong correlation between SLP anomalies over the western Mediterranean and the local zonal wind in the Alboran Sea (e.g., Crepon 1965; Cheney and Doblar 1982; Sarhan et al. 2000; Vargas-Yáñez et al. 2002; Macías et al. 2007b) as shown in Fig. 5a. Consequently, both zonal wind and SLP anomalies have positive (negative) correlations with the AJ velocity (Fig. 5b, c). The angle, however, seems to be more controlled by the local wind conditions (Fig. 5d) than by the remote SLP conditions (Fig. 5e). A substantial increase of the angle is only associated with negative zonal wind values while SLP anomalies during the largest excursions of the $\mathrm{AJ}$ direction were around 0 .

Also, it is necessary to stress that all the analysis above were made using surface velocity values where the AJ intensity is typically maximum. Thus, we tested also if considering the whole integrated velocity of the AJ (and not only its 
surface values) could change our simulations results. We found (not shown) that the pattern is quite similar to the ones described above for the surface values. The AJ angle-module relationship is the same as the one shown in Fig. 3, only the module values being slightly lower as expected for integrated values. We also computed the total water going in (inflow) and out (outflow) the Mediterranean basin for each time step and found a high negative correlation between those flow values $(R=-0.84, p<0.01)$. Henceforth, a negative correlation between total water outflow and local zonal wind was found $(R=-0.72, p<0.01)$ as also reported by Boutov et al. (2014). So, the effects of atmospheric forcing are influencing the entire water column dynamics and not only its first few meters.

Given the difficulty to separate efficiently the contribution of each atmospheric forcing to the AJ dynamics (see Fig. 4), it is necessary to perform a process-based study by artificially manipulating the atmospheric forcing to the model (see section 2.3). When local wind is excluded (simulation R1), the temporal evolution of the angle of the AJ (Fig. 6a) shows remarkable similitudes with the RR simulation. The main differences could only be observed on the extreme migration events simulated for fall of 2001 and 2007 in RR as they are largely reduced for R1. This is in agreement with the anglewind relationships mentioned above (Fig. 5d) and further confirms the need of negative zonal winds to force the AJ southwards as previously hypothesized by Macías et al. (2007b). In simulation R1, the correlation between SLP and AJ module is very similar to the original pattern (Fig. 6b) with faster AJ associated with negative SLP anomalies and slower AJ with positive SLP anomalies values.

When the SLP is set to its mean value throughout the entire simulation period (simulation $\mathrm{R} 2$ ), the AJ dynamics is almost identical to the one simulated in RR (Fig. 6c, d). The most obvious difference with R1 exposed above is that the large southward excursions of the AJ in 2001 and 2007 are again simulated by the model in R2. This is in consistence with the lack of obvious relationship between AJ angle and SLP shown in Fig. 5e.

The apparent lack of reaction of the AJ seasonal dynamics to such dramatic changes of the local wind conditions and the SLP over the Mediterranean is, indeed, a quite unexpected result as a substantial fraction of the AJ variability has been typically attributed to atmospheric pressure variations influencing barotropic water interchanges through Gibraltar (e.g., Candela et al. 1989; García-Lafuente et al. 2002). However, here, we must stress that we are considering relatively larger time scales as only integrated monthly results are being considered. The direct effects of local and remote atmospheric forcings are expected to be larger at subinertial scales (from several days to few weeks) (e.g., Macías et al. 2009, 2011; Vázquez et al. 2008).

We could also focus on the most outstanding events clearly visible in the time series, the southward migration of the $\mathrm{AJ}$ in fall 2001 and fall 2007 (Fig. 2a). The 2001 anomaly was described almost 10 years ago by Béranger et al. (2005) who, by using a numerical hydrodynamic model of the region, reported a substantial drop of the AJ velocity during the final months of year 2001. A more recent modeling work (Peliz et al. 2013) also found a strong diminution of the maximum velocity of the AJ during fall 2001. The separation of the AJ from the Spanish shore during this period provoked a relaxation of the general circulation patterns, especially in the coastal region eastward of the strait. The lack of strong surface circulation during this time period in the NW Alboran Sea has been also observed from satellite altimetry data (e.g., Renault et al. 2012; Ruiz et al. 2013).

The causes of this anomaly in the model simulation were further explored in Boutov et al. (2014) using the same modeling approach as Peliz et al. (2013). As their model is only forced by the local atmospheric conditions (their model setup did not incorporate the entire Mediterranean Sea), they conclude that such a significant drop of the AJ velocity should be caused by the local action of the atmosphere on the surface layer. From our modeling exercise, this hypothesis seems quite likely as a strong negative anomaly in local zonal wind $\left(-2.15 \mathrm{~m} \mathrm{~s}^{-1}\right)$ was registered over the Alboran Sea during October-November-December 2001. Also, in our simulations without winds (R1 and R3), this increase in the AJ angle is not observed (Fig. 6a, e), further supporting the locally forced origin of this perturbation.

The second occasion when the AJ strongly veers southwards happened during fall 2007 (Fig. 2a). Again during this time, mean zonal wind was clearly negative $\left(-1.85 \mathrm{~m} \mathrm{~s}^{-1}\right)$, and again, this event is not rightly reproduced in the simulations with no wind over the Alboran Sea (Fig. 6a, e). Henceforth, the locally forced origin for this event is also likely. In previous modeling exercises covering this time period, a similar drop in the AJ velocity and a shift southward at the end of 2007 has been described (Peliz et al. 2013; Boutov et al. 2014). Also, in current data from an ADCP measuring the intensity of the Mediterranean outflow within the main channel of the strait, a substantial increase in water velocity was registered for winter 2007-2008 (Sánchez-Román et al. 2009). Henceforth, this event of inflow reduction (and increased outflow) reproduced by our model seems to have really happened.

However, these previous experiences did not answer to the question of what is causing the very clear seasonal cycle typically described for the AJ. Even if the AJ monthly characteristics (flowing speed and direction) seems to be correlated with the monthly values of local wind and SLP (see Fig. 5), it does not necessarily mean that there is a causality link between the different variables (Liang 2014). SLP and wind did have a seasonal cycle (Candela et al. 1989; Dorman et al. 1995), but from the experiments above, it seems quite clear that those cycles are not responsible for the seasonality in the AJ. 
It has been described that a large fraction ( $93 \%)$ of the water flow through the Strait of Gibraltar is, indeed, maintained by the continuous transformation of surface Atlantic water into deep Mediterranean water within the Mediterranean basin (Basheck et al. 2001), i.e., by the Mediterranean thermohaline circulation (MTHC). This MTHC is typically forced by deep water formation events during winter months (nominally from January to March) in some specific places within the western (i.e., Gulf of Lion), central (i.e., Southern Adriatic), and eastern (i.e., around Crete) Mediterranean basins (e.g., D’Ortenzio et al. 2003). This is clearly shown by the mean value of the winter mixed layer depth (MLD) simulated by the model using the complete atmospheric forcings (Fig. 7a) as regions with large winter MLD coincide with deep water formation areas (stars in Fig. 7) described elsewhere (e.g., Siokou-Frangou et al. 2010). As clearly seen in the time series of MLD in those places and for simulation RR (solid lines in Fig. 7c) almost every winter, the upper layer of the water column is well mixed through a considerable depth indicating favorable conditions for deep water formation. On the contrary, when wind is set to zero and no precipitation is considered in the model (simulation R4), no winter mixing event is simulated (dashed lines in Fig. 7c) with the entire basin presenting an abnormally shallow winter MLD (Fig. 7b).

The behavior of the AJ in this last simulation changed dramatically as the entire circulation thorough the strait reverses, with a deep inflow of Atlantic waters (not shown) and a surface outflow of Mediterranean waters (Fig. 8). As commented above, even if the total variability of $\mathrm{AJ}$ angle in simulation R4 is very small, there is still an annual cycle as the main contributing signal. The presence of this annual cycle in this simulation with no atmospheric forcing variability could be related with the monthly climatologic conditions imposed at the western boundary of the model (see model description in section 2.1). Results from R4 support the importance of the deep water formation to explain the water circulation through the strait (e.g., Basheck et al. 2001), and it is indirect evidence that one of the main causes of the seasonality of the AJ is the MTHC cycle. During winter months, deep mixing and deep water formation are more acute, which provoke a large volume of surface water to be transported into the deep layers. This creates a "deficit" of surface waters that should be compensated by a large entrance of Atlantic waters into the basin. This, in turn, explains the stronger AJ during the first months of the year flowing quicker and with a northwesterly direction as shown in Fig. 2.

However, if the deep water formation rate (and associated $\mathrm{MTHC}$ ) was the only factor influencing the AJ dynamics, it should be expected to see a different shape of the AJ annual cycle than the one shown in Fig. 4b. If MTHC was solely responsible for the $\mathrm{AJ}$ seasonality, a sharper decline of its intensity should be simulated after the winter months, so some additional process should be contributing to the progressive weakening of the $\mathrm{AJ}$ along the summer until its minimum in fall. This secondary factor could be the evapotranspiration annual cycle that presents maximum values during summer when evaporation is high and precipitation is lowest, a secondary maximum during winter due to the strong evaporation associated with cold dry winds, and relative minima in spring and fall (e.g., Mariotti et al. 2002). The excess evaporation during summer demands a relative large amount of Atlantic waters to be imported in order to maintain the sea level, which could explain why the AJ velocity (i.e., inflow through the strait) is still relevant during summer months even if no MTHC is taking place. Towards the fall, evapotranspiration is reduced because of the progressive cooling of air temperature, but still no significant MTHC is taking place. No significant MTHC and a much reduced evapotranspiration translate in a very low demand for surface waters into the Mediterranean basin and could help explain why the AJ shows a recurrent minimum during fall in every simulated year.

\section{Conclusions}

The proposed model seems to indicate quite clearly that local and remote atmospheric forcings are not relevant sources to explain the seasonal dynamics of the AJ within the Alboran Sea. This is so even if at monthly time scales significant correlations between local zonal winds, sea level pressure, and AJ velocity could be found. Local wind forcing at this scale seems to be of relevance, though, to explain some extreme collapse events recorded during particular years (e.g., 2001 and 2007) while sea level pressure variation did not show any significant effect on the simulated AJ behavior. From an additional simulation, it seems that the combination of the seasonal cycles of deep water formation and evapotranspiration are much more relevant for the seasonal cycle of the AJ. The circulation model used here, even being an approximation to the real system, seems to capture the main characteristics of the AJ dynamics and could be a useful tool to explore future changes of hydrological conditions of the Alboran Sea under predicted climate change scenarios.

Acknowledgments DM was supported by a Grantholder Cat.30 position of the Joint Research Center of the European Commission. The use of ERA-interim atmospheric data downloaded from the ECMWF MARS server is greatly acknowledged. The authors thank the JPL-PODAAC for the Pathfinder SST observations. The data used in the present research could be requested to D. Macias at diego.macias-moy@jrc.ec.europa.eu.

Open Access This article is distributed under the terms of the Creative Commons Attribution 4.0 International License (http:// creativecommons.org/licenses/by/4.0/), which permits unrestricted use, distribution, and reproduction in any medium, provided you give appropriate credit to the original author(s) and the source, provide a link to the Creative Commons license, and indicate if changes were made. 


\section{References}

Armi L, Farmer D (1988) The flow of Mediterranean water through the Strait of Gibraltar. Prog Oceanogr 21:41-82

Arnone RA, Wiesenburg DA, Saunders KD (1990) The origin and characteristics of the Algerian current. J Geophys Res 95:1587-1598

Basheck B, Send U, García Lafuente J, Candela J (2001) Transport estimates in the Strait of Gibraltar with a tidal inverse model. J Geophys Res 106:31033-31044

Béranger K, Mortier L, Crépon M (2005) Seasonal variability of water transport through the Straits of Gibraltar, Sicily and Corsica, derived from a high-resolution model of the Mediterranean circulation. Prog Oceanogr 66:231-250

Boutov D, Peliz A, Miranda PMA, Soares PMM, Cardoso RM, Prieto L, Ruiz J, García-Lafuente J (2014) Inter-annual variability and long term predictability of exchanges through the Strait of Gibraltar. Glob Planet Chang 114:23-37

Bretherton CS, Smith C, Wallace JM (1992) An intercomparison of methods for finding coupled patterns in climate data. J Clim 5(6): $541-560$

Bruno M, Alonso JJ, Cózar A, Vidal J, Ruiz-Cañavate A, Echevarría F, Ruiz J (2002) The boiling-water phenomena at Camarinal Sill, the Strait of Gibraltar. Deep-Sea Res II 49:4097-4113

Burchard H, Bolding K (2002) GETM, a general estuarine transport model, scientific documentation. Technical report. European Commission, Ispra

Candela J, Winant C, Bryden H (1989) Meteorologically forced subinertial flows through the Strait of Gibraltar. J Geophys Res 94: 12667-12679

Candela Perez J (1991) The Gibraltar Strait and its role in the dynamics of the Mediterranean Sea. Dyn Atmos Oceans 15:267-298

Catalán IA, Macías D, Solé J, Ospina-Alvarez A, Ruiz J (2013) Stay off the motorway: resolving the pre-recruitment life history dynamics of the European anchovy in the SW Mediterranean through a spatiallyexplicit individual-based model (SEIBM). Prog Oceanogr 111:140153

Cheney RE, Doblar RA (1982) Structure and variability of the Alborán Sea frontal system. J Geophys Res 87:585-594

Crepon M (1965) Influence de la pression atmospherique sur le niveau moyen de la Mediterranee Occidentale et sur le flux a travers le detroit de Gibraltar. Cah Oceanogr 1:15-32

D’Ortenzio F, Ragni M, Marullo S, Ribera d'Alcala M (2003) Did biological activity in the Ionian Sea change after the Eastern Mediterranean Transient? Results from the analysis of remote sensing observations. J Geophys Res 108:8113. doi:10.1029/ 2002JC001556

Dee DP, Uppala SM, Simmons AJ, Berrisford P, Poli P, Kobayashi S, Andrae U, Balmaseda MA, Balsamo G, Bauer P, Bechtold P, Beljaars ACM, van de Berg L, Bidlot J, Bormann N, Delsol C, Dragani R, Fuentes M, Geer AJ, Haimberger L, Healy SB, Hersbach H, Holm EV, Isaksen L, Kallberg P, Kohler M, Matricardi M, McNally AP, Monge-Sanz BM, Morcrette JJ, Park BK, Peubey C, de Rosnay P, Tavolato C, Thepaut JN, Vitart F (2011) The ERA-interim reanalysis: configuration and performance of the data assimilation system. Q J R Meteorol Soc 137:553-597. doi:10.1002/qj.828

Dorman CE, Beardsley RC, Limeburner R (1995) Winds in the Strait of Gibraltar. Q J R Meteorol Soc 121:1903-1921

García-Gorriz E, Carr ME (1999) The climatological annual cycle of satellite-derived phytoplankton pigments in the Alboran Sea. Geophys Res Lett 26:2985-2988

García-Lafuente J, Cano N, Vargas M, Rubín JP, Hernandez-Guerra A (1998) Evolution of the Alboran Sea hydrographic structures during July 1993. Deep Sea Res I 45:39-65
García-Lafuente J, Alvarez E, Vargas J, Ratsimandresy W (2002) Subinertial variability in the outflow through the Strait of Gibraltar. J Geophys Res 107(C10):3168

Garret C, Bormans M, Thompson K (1990) Is the exchange through the Strait of Gibraltar maximal or submaximal? In: Pratt LJ (ed) The Physical Oceanography of Sea Straits 318 NATO ASI Series. Springer, Netherlands. doi:10.1007/978-94-009-0677-8_13

Herburn GW, La Violette PE (1990) Variations in the structure of the anticyclonic gyres found in the Alboran Sea. J Geophys Res 95: $1599-1613$

Huertas IE, Ríos AF, García-Lafuente J, Navarro G, Makaoui A, Sánchez-Román A, Rodriguez-Galvez S, Orbi A, Ruíz J, Pérez FF (2012) Atlantic forcing of the Mediterranean oligotrophy. Glob Biochem Cycles 26, GB2022

Izquierdo A, Tejedor L, Sein DV, Backhaus JO, Brandt P, Rubino A, Kagan BA (2001) Control variability and internal bore evolution in the Strait of Gibraltar: a 2-D two-layer model study. Estuar Coast Shelf Sci 53:637-665

Kantha LH, Clayson CA (2000) Numerical models of oceans and oceanic processes. Academic Press, 750 pp, ISBN: 9780124340688

La Violette PE (1984) The advection of submesoscale thermal features in the Alboran Sea gyre. J Phys Oceanogr 14:550-565

Lacombe H (1971) Le Dètroit de Gibraltar; Oceanographique Physique. In: Mèmorie explicatif de la carte gèotechnique de Tanger au 1/ 250000:222, p 111-146. Notes et Mémories Service Gèologique du Marrocco

Lanoix F (1974) Etude hydrologique et dynamique de la mer d'Alboran. North Atlantic Treaty, 66, 32pp

Liang XS (2014) Unraveling the cause-effect relation between time series. Phys Rev E 90. doi:10.1103/PhysRevE.90.052150

Macías D, García CM, Echevarría F, Vázquez-Escobar A, Bruno M (2006) Tidal induced variability of mixing processes on Camarinal Sill (Strait of Gibraltar). A pulsating event. J Mar Syst 60:177-192

Macías D, Martin AP, García Lafuente J, García CM, Yool A, Bruno M, Vázquez A, Izquierdo A, Sein D, Echevarría F (2007a) Mixing and biogeochemical effects induced by tides on the AtlanticMediterranean flow in the Strait of Gibraltar. An analysis through a physical-biological coupled model. Prog Oceanogr 74:252-272

Macías D, Navarro G, Echevarría F, García CM, Cueto JL (2007b) Phytoplankton pigment distribution in the north-western Alboran Sea and meteorological forcing: a remote sensing study. J Mar Res 65:523-543

Macías D, Bruno M, Echevarría F, Vázquez A, García CM (2008) Metereologically-induced mesoscale variability of the northwestern Alboran Sea (southern Spain) and related biological patterns. Estuar Coast Shelf Sci 78:250-266

Macías D, Navarro G, Bartual A, Echevarría F, Huertas IE (2009) Primary production in the Strait of Gibraltar: carbon fixation rates in relation to hydrodynamic and phytoplankton dynamics. Estuar Coast Shelf Sci 83:197-210

Macías D, Catalán IA, Solé J, Morales-Nin B, Ruiz J (2011) Atmospheric-induced variability of hydrological and biogeochemical signatures in the NW Alboran Sea. Consequences for the spawning and nursery habitats of European anchovy. Deep-Sea Res I 58:1175-1188

Macías D, Garcia-Gorriz E, Stips A (2013) Understanding the causes of recent warming of Mediterranean waters. How much could be attributed to climate change? Plos One 8(11):e81591. doi:10.1371/ journal.pone. 00815

Macías D, Castilla-Espino D, García-del-Hoyo JJ, Navarro G, Catalán IA, Renault L, Ruiz J (2014a) Consequences of a future climatic scenario for the anchovy fishery in the Alboran Sea (SW Mediterranean): a modeling study. J Mar Syst 135:150-159

Macías D, Stips A, Garcia-Gorriz E (2014b) The relevance of deep chlorophyll maximum in the open Mediterranean Sea evaluated through 
3D hydrodynamic-biogeochemical coupled simulations. Ecol Model 281:26-37

Macías D, Garcia-Gorriz E, Piroddi C, Stips A (2014c) Biogeochemical control of marine productivity in the Mediterranean Sea during the last 50 years. Glob Biochem Cycles 28:897-907. doi:10.1002/ 2014GB004846

Mariotti A, Struglia MV, Zeng N, Lau KM (2002) The hydrological cycle in the Mediterranean region and implications for the water budget of the Mediterranean Sea. J Clim 15:1674-1690

Navarro G, Vázquez A, Macías D, Bruno M, Ruiz J (2011) Understanding the patterns of biological response to physical forcing in the Alborán Sea (western Mediterranean). Geophys Res Lett 38, L23606. doi:10.1029/2011GL049708

Peliz A, Boutov D, Teles-Machado A (2013) The Alboran Sea mesoscale in a long term high resolution simulation: statistical analysis. Ocean Model 72:32-52

Perkins H, Kinder T, La Violette P (1990) The Atlantic inflow in the western Alboran Sea. J Phys Oceanogr 20:242-263

Preller RH (1986) A numerical model study of the Alboran Sea Gyre. Prog Oceanogr 16:113-146

Ramírez-Romero E, Macías D, Bruno M, Reyes E, Navarro G, García CM (2013) Submesoscale tidally-induced biogeochemical patterns in the Strait of Gibraltar. Estuar Coast Shelf Sci 101:24-32

Renault L, Oguz T, Pascual A, Vizoso G, Tintore J (2012) Surface circulation in the Alboran Sea (western Mediterranean) inferred from remotely sensed data. J Geophys Res 117 , C08009

Ruiz J, Echevarría F, Font J, Ruiz S, García E, Blanco JM, JiménezGómez F, Prieto L, González-Alaminos A, García CM, Cipollini P, Snaith H, Bartual A, Reul A, Rodríguez V (2001) Surface distribution of chlorophyll, particles and gelbstoff in the Atlantic Jet of the Alborán Sea: from submesoscale to subinertial scales of variability. J Mar Syst 29:277-292

Ruiz J, Macías D, Rincon M, Pascual A, Catalan IA, Navarro G (2013) Recruiting at the edge: kinetic energy inhibits anchovy populations in the western Mediterranean. Plos One 8(2), e55523. doi:10.1371/ journal.pone. 0055523

Sánchez-Garrido JC, García-Lafuente J, Álvarez-Fanjul E, García-Sotillo M, de los Santos FJ (2013) What does cause the collapse of the
Western Alboran Gyre? Results of an operational ocean model. Prog Oceanogr 116:142-153

Sánchez-Román A, García-Lafuente J, Carillo A, Criado-Aldeanueva F (2009) Transport estimates at the western section of the Strait of Gibraltar: a combined experimental and numerical modelling study. J Geophys Res 114, C06002

Sannino G, Bargagli A, Artale V (2002) Numerical model of the mean exchange through the Strait of Gibraltar. J Geophys Res 107:3044

Sannino G, Bargagli A, Artale V (2004) Numerical modeling of the semidiurnal tidal exchange through the Strait of Gibraltar. J Geophys Res 109, C05011. doi:10.1029/2003JC002057

Sannino G, Carrillo A, Artale V (2007) Three-layer view of transports and hydraulics in the Strait of Gibraltar: a three-dimensional model study. J Geophys Res 112, C03010

Sarhan T, García-Lafuente J, Vargas M, Vargas JM, Plaza F (2000) Upwelling mechanisms in the northwestern Alboran Sea. J Mar Syst 23:317-331

Siokou-Frangou I, Christaki U, Mazzocchi MG, Montresor M, Ribera d'Alcalá M, Vaqué D, Zingone A (2010) Plankton in the open Mediterranean Sea: a review. Biogeosciences 7:1543-1586

Stips A, Bolding K, Pohlman T, Burchard H (2004) Simulating the temporal and spatial dynamics of the North Sea using the new model GETM (general estuarine transport model). Ocean Dyn 54:266-283

Vargas-Yáñez M, Plaza M, García-Lafuente J, Sarhan T, Vargas JM, Vélez-Belchi P (2002) About the seasonal variability of the Alboran Sea circulation. J Mar Syst 35:229-248

Vázquez A, Bruno M, Izquierdo A, Macías D (2008) The effect of meteorologically forced subinertial flows on internal waves generation at the main sill of the Strait of Gibraltar. Deep-Sea Res I 57:12771283

Viúdez A, Haney RL, Tintoré J (1996) Circulation in the Alborán Sea as determined by quasi-synoptic hydrographic observations. Part II: mesoscale ageostrophic motion diagnosed through density dynamical assimilation. J Phys Oceanogr 26:706-724

Viúdez A, Pinot J, Haney R (1998) On the upper layer circulation in the Alboran Sea. J Geophys Res 103:21653-21666

Werner FW, Cantos-Figureloa A, Parilla G (1988) A sensitivity study of reduced-gravity channel flows with application to the Alboran Sea. J Phys Oceanogr 18:373-383 